\title{
Implementasi Family Development Session Program Keluarga Harapan
}

\section{Implementation of the Family Development Session of the Family of Hope Program}

\author{
Evan Notatema Hia*, Matias Siagian \& Nurman Achmad \\ Program Studi Magister Studi Pembangunan, Fakultas Ilmu Sosial Dan Ilmu Politik, \\ Universitas Sumatera Utara, Indonesia
}

Diterima: 17 Agustus 2020; Disetujui: 15 Desember 2020; Dipublish: 31 Jaunari 2021

\begin{abstract}
Abstrak
Penelitian ini bertujuan untuk mengetahui implementasi Family Development Session program keluarga harapan di wilayah Kelurahan Pekan Selesai Kecamatan Selesai Kabupaten Langkat Sumatera Utara. Jenis penelitian ini menggunakan pendekatan deskriptif kualitatif, metode pengumpulan data berupa observasi, dokumentasi dan wawancara kepada para informan yang sudah ditentukan. Hasil Penelitian ini menunjukkan bahwa para agen pelaksana Dinas Sosial dan SDM PKH sudah melakukan sosialisasi tentang FDS di mulai dari tingkat kabupaten, kecamatan, kelurahan dan kepada penerima manfaat, adanya pendamping sosial dalam pelaksanaan identifikasi masalah menggunakan teknik MPA (Methode partisipatory Assesment) kepada penerima. Selanjutnya tahap pembelajaran materi menunjukkan bahwa kepatuhan pendamping sosial juga sudah melaksanakan pembelajaran modul FDS, namun masih ditemukan kendala penggunaan komponen bahan ajar kepada penerima manfaat. Tahap pelaporan menunjukkan pendamping sosial sudah patuh dalam melakukan pelaporan kegiatan pelaksanaan FDS setiap bulannya baik secara laporan manual dengan mengumpulkan hard copy maupun laporan berbasis aplikasi E-PKH.
\end{abstract}

Kata Kunci: Implementasi; Family Development Session; Program Keluarga Harapan

\begin{abstract}
This study aims to determine the implementation of the Family Development Session of the family hope program in the Kelurahan Pekan Selesai, Selesai Subdistrict, Langkat Regency of North Sumatra. This type of research uses a qualitative descriptive approach, data collection methods in the form of observation, documentation and interviews with the informants who have been determined. The results of this study indicate that the implementing agencies of the PKH Social and HR Service have carried out socialization about FDS at the district, sub-district, sub-district level and to beneficiaries, the existence of social assistants in implementing problem identification using the MPA technique (participatory assessment method) to recipients. Furthermore, the material learning stage shows that the compliance of the social facilitator has also implemented the FDS module learning, but there are still obstacles to the use of teaching material components for beneficiaries. The reporting stage shows that the social facilitator has complied with reporting on FDS implementation activities every month either manually by collecting hard copies or reports based on the E-PKH application.
\end{abstract}

Keywords: Implementation; Family Development Session; Family Hope Program

How to Cite: Hia, E.N., Siagian, M., \& Achmad, N. (2021). Implementasi Family Development Session Program Keluarga Harapan. PERSPEKTIF, 10 (1): 128-139.

*Corresponding author:

E-mail: evanhia@gmail.com
ISSN 2085-0328 (Print)

ISSN (Online) 


\section{PENDAHULUAN}

Kemiskinan sampai saat ini masih menjadi permasalahan mendasar pembangunan di berbagai negara, sehingga menjadi perhatian khusus bagi pemerintah dalam membuat sebuah kebijakan. Menurut Bank Dunia (Akbar 2015), kemiskinan adalah kehilangan kesejahteraan (well-being) yang artinya kondisi serba kekurangan yang mengakibatkan seseorang tidak mampu mencapai derajat hidup layak. Badan Pusat Statistik (BPS) mengartikan kemiskinan sebagai ketidakmampuan untuk memenuhi standar minimum kebutuhan dasar yang meliputi kebutuhan makanan maupun nonmakanan (Cahyat, 2004). Secara umum, kemiskinan didefinisikan sebagai kondisi saat seseorang atau sekelompok orang tidak mampu memenuhi hak-hak dasarnya untuk mempertahankan dan mengembangkan kehidupan yang bermartabat.

Masalah kemiskinan tidak hanya terjadi di negara-negara tertinggal dan berkembang saja, bahkan negara maju pun mengalami hal yang sama, sehingga dampak dari kemiskinan warga negara sangat berpengaruh terhadap kondisi kesejahteraan negara tersebut. Indikasi dari kemiskinan dapat dilihat dari kenyataan seperti ketidaktersediaannya air bersih, gizi buruk, rendahnya pendidikan, banyaknya pengangguran dan lain-lain. Permasalahan kemiskinan di berbagai negara, khususnya negara sedang berkembang, telah menarik perhatian khusus bagi Perserikatan Bangsa-bangsa (PBB) dengan berkomitmen menghapus kemiskinan melalui program Sustainable Development Goals (SDGs). Program tersebut dijabarkan ke dalam 17 point pokok yang ingin dicapai pada tahun pada 2030, yaitu meliputi (1) Tanpa kemiskinan, (2) Tanpa kelaparan, (3) Kesehatan yang baik dan kesejahteraan, (4) pendidikan berkualitas, (5) Kesetaraan gender, (6) Air bersih dan sanitasi, (7) Energi bersih dan terjangkau, (8) Pertumbuhan ekonomi dan pekerjaan yang layak, (9) Industri, inovasi dan infrastruktur, (10) Mengurangi kesenjangan, (11) Keberlanjutan kota dan komunitas, (12) Konsumsi dan produksi bertanggung jawab, (13) Aksi terhadap iklim, (15) Kehidupan di darat, (16) Institusi peradilan yang kuat dan kedamaian, (17) Kemitraan untuk mencapai tujuan (sutopo, 2014).
Badan Pusat Statiskik (BPS) pada bulan Maret 2018 mengeluarkan data hasil survei dengan jumlah penduduk miskin (penduduk dengan pengeluaran per kapita per bulan di bawah garis kemiskinan) di Indonesia mencapai 25,95 juta orang $(9,82$ persen). Persentase penduduk miskin di daerah perkotaan pada Maret 2018 menjadi 7,02 persen. Sementara itu, persentase penduduk miskin di daerah perdesaan pada berada pada 13,20 persen. Memang secara data jumlah penduduk miskin di Indonesia dari tahun ke tahun menunjukan penurunan. Sebagai pembanding dengan kondisi September 2017 yang sebesar 26,58 juta orang $(10,12$ persen). Pemerintah sebagai pemegang peran eksekutif masih memiliki pekerjaan rumah dalam memaksimalkan penurunan angka kemiskinan warga negaranya.

Untuk menjamin peningkatan ekonomi dan kesejahteraan masyarakatnya maka, pembangunan nasional harus dilaksanakan disegala sektor kehidupan bangsa. Oleh karena itu pemerintah sudah banyak mengeluarkan kebijakan yang mampu menekan permasalahan kemiskinan di Indonesia. Penanggulangan kemiskinan yang komprehensif memerlukan keterlibatan berbagai pemangku kepentingan. Pemerintah pusat, pemerintah daerah, dunia usaha (sektor swasta) dan masyarakat merupakan pihakpihak yang mempunyai tanggungjawab sama terhadap penanggulangan kemiskinan. Pemerintah dari tahun ke tahun telah mengeluarkan berbagai kebijakan penanggulangan kemiskinan melalui berbagai program dalam upaya pemenuhan kebutuhan dasar warga negara secara layak, meningkatkan kesejahteraan ekonomi keluarga miskin, penguatan kelembagaan sosial ekonomi masyarakat serta melaksanakan pembangunan infrastruktur di daerah tertinggal dalam upaya mencapai pemerataan pertumbuhan ekonomi.

Kebijakan penanggulangan kemiskinan dari masa-kemasa sudah banyak diterapkan di Indonesia, namun program-program penanggulanag kemiskinan yang sudah diimplemtasikan masih belum maksimal menurunkan angka kemiskinan sesuai dengan target pencapaian yang di inginkan. Oleh karena itu pemerintah terus mentransformasi program penangulangan kemiskinan agar lebih efektif dalam menurunkan angka 
kemiskinan. Kebijakan pemerintah dalam rangka peningkatan efektivitas dan efisiensi penyaluran bantuan sosial serta terwujudnya prinsip 4T (Tepat Sasaran, Tepat Waktu, Tepat Jumlah dan Tepat Administrasi) dan mendorong keuangan inklusif, melalui arahan Presiden Republik Indonesia agar bantuan sosial dan subsidi yang selama ini dilakukan dengan pemberian tunai diubah konsepnya menjadi non tunai. Penyaluran bantuan sosial non tunai dilakukan dengan melakukan sistem perbankan, hal ini dilakukan untuk meningkatakan transparansi dan akuntabilitas program penyaluran bantuan sosial agar mudah dikontrol.

Salah satu upaya penanggulangan percepatan kemiskinan yang dilaksanakan oleh pemerintah sejak tahun 2007 yaitu Program Bantuan Langsung Tunai Bersyarat yang kemudian dikenal dengan nama Program Keluarga Harapan (PKH). Sesuai Peraturan Menteri Sosial Nomor 1 tahun 2018 Program Keluarga Harapan yang selanjutnya disingkat PKH adalah program pemberian bantuan sosial bersyarat kepada keluarga/atau seseorang miskin dan rentan yang terdaftar dalam data terpadu program penanganan fakir miskin, diolah oleh Pusat Data dan Informasi Kesejahteraan Sosial dan ditetapkan sebagai keluarga penerima manfaat PKH.

Program Keluarga Harapan sebagai salah satu program perlindungan sosial juga dikenal di dunia internasional dengan istilah Conditional Cash Transfers (CCT), ditetapkan melalui Peraturan Menteri Sosial Nomor 1 Tahun 2018 tentang Program Keluarga Harapan. Peraturan ini diterbitkan untuk mendukung pelaksanaan penyaluran program perlindungan sosial yang terencana, terarah dan berkelanjutan dalam bentuk Program Keluarga Harapan (PKH) sebagai bantuan sosial bersyarat yang bertujuan untuk mengurangi beban pengeluaran dan meningkatkan pendapatan keluarga miskin dan rentan. Bantuan sosial PKH sebagai salah satu upaya mengurangi kemiskinan dan kesenjangan dengan mendukung perbaikan aksesibilitas terhadap layanan kesehatan, pendidikan, dan kesejahteraan sosial guna meningkatkan kualitas hidup keluarga miskin dan rentan.

Tujuan PKH sesuai Peraturan Menteri Sosial Nomor 1 Tahun 2018 tentang Program Keluarga Harapan Pasal 2 antara lain;
Meningkatkan taraf hidup keluarga penerima manfaat melalui akses layanan pendidikan, kesehatan dan kesejahteraan social; Mengurangi beban pengeluaran dan meningkatkan pendapatan keluarga miskin dan rentan; Menciptakan perubahan perilaku dan kemandirian keluarga penerima manfaat dalam mengakses layanan kesehatan dan pendidikan serta kesejahteraan sosial; Mengurangi kemiskinan dan kesenjangan; Mengenalkan manfaat produk dan jasa keuangan formal kepada keluarga penerima manfaat.

Sasaran Program Keluarga Harapan disebut juga dengan istilah Keluarga Penerima Manfaat (KPM) yaitu keluarga miskin dan rentan berdasarkan data terpadu program penanganan fakir miskin yang memiliki komponen kesehatan, pendidikan, dan kesejahteraan sosial. Program Keluarga Harapan di Indonesia sudah mulai diimplementasikan sejak tahun 2007 di beberapa Kabupaten/Kota. Langkat sebagai salah satu kabupaten yang berada di wilayah Sumatera Utara menjadi sasaran PKH sebagai wujud penanggulangan kemiskinan di mulai sejak tahun 2015 dengan jumlah penerima program saat itu sekitar 26.940 KPM yang tersebar di 23 Kecamatan. Kemudian pada tahun 2018 sebagai wujud perluasan program jumlah bertambah menjadi 44.115 KPM. Proses pelaksanaan Program Keluarga Harapan di wilayah Kabupaten Langkat selalu dibarengi dengan monitoring keluarnya keluarga penerima manfaat atau yang dikenal dengan istilah Graduasi Mandiri. Sesuai Permensos Nomor 1 Tahun 2018 tentang Program Keluarga Harapan mendefenisikan graduasi mandiri sebagai kondisi dimana penerima manfaat lepas dari bantuan sosial yang selama ini diberikan pemerintah, dikarenakan penerima manfaat tersebut menyatakan diri telah mandiri secara ekonomi serta tidak memenuhi syarat kondisional sebagai penerima PKH.

Untuk mencapai salah satu tujuan Program Keluarga Harapan (PKH) menciptakan perubahan perilaku dan kemandirian keluarga penerima manfaat dalam mengakses layanan kesehatan, pendidikan serta kesejahteraan sosial, maka Kementerian Sosial menerapkan sebuah metode pengubahan perilaku kepada KPM yang dikenal dengan istilah FDS (Family 
Development Session). Sesuai Peraturan Menteri Sosial Nomor 1 tahun 2018 tentang Program keluarga Harapan mendefenisikan Family Development Session (FDS) yang juga dikenal dengan istilah Pertemuan Peningkatan Kemampuan Keluarga (P2K2) adalah proses belajar secara terstruktur untuk mempercepat terjadinya perubahan perilaku pada keluarga penerima manfaat PKH. Sasaran dari metode ini adalah keluarga penerima manfaat PKH yang gabung dalam beberapa kelompok, dengan ketentuan setiap kelompok masingmasing berjumlah maksimal $30 \mathrm{KPM}$.

Program perlindungan sosial adalah bagian penting dalam strategi pembangunan terutama bagi negara-negara berkembang. Perlindungan sosial bertujuan mengurangi risiko sosial, meningkatkan kesetaraan, mengurangi kemiskinan karena potensi manfaat jangka panjang perubahan perilaku positif akibat kondisionalitas dalam CCT " $(A$ Philosophical Framework for Conditional Cash Transfers, Jaron Abelsohn, 2011). Sebagaimana pentingnya pelaksanaan metode perubahan perilaku dalam menciptakan kemandirian Keluarga Penerima Manfaat Program Keluarga Harapan, maka adapun tujuan pelaksanaan FDS (Family Development Session) sebagai berikut; Meningkatkan pengetahuan praktis mengenai kesehatan, pendidikan dan pengasuhan, ekonomi, dan perlindungan anak; Meningkatkan pengetahuan dan pemahaman keluarga PKH mengenai kondisi, kebutuhan dan perawatan yang dibutuhkan lansia dan orang dengan disabilitas berat; Membangun kesadaran peserta PKH terhadap pentingnya pemenuhan kewajiban dalam bidang kesehatan dan pendidikan dalam $\mathrm{PKH}$; Menjaga dan memperkuat perubahan perilaku positif terkait pendidikan dan pengasuhan, kesehatan, ekonomi dan perlindungan anak; Menjaga dan memperkuat perubahan perilaku positif terkait perawatan dan pemeliharaan terhadap lansia dan orang dengan disabilitas berat; Meningkatkan keterampilan orang tua dalam bidang pendidikan dan pengasuhan anak, kesehatan, ekonomi dan perlindungan anak; Meningkatkan kemampuan peserta untuk mengenali potensi yang ada pada diri dan lingkungannya agar dapat digunakan dalam peningkatan kesejahteraan keluarga dan masyarakat.

Kegiatan FDS diimplementasikan kepada masyarakat dengan konsep belajar dalam kelompok yang sudah dibentuk, hal ini bertujuan untuk meningkatkan kemampuan dan pengetahuan penerima manfaat dengan modul-modul pembelajaran yang ada. Kegiatan FDS dilaksanakan satu kali dalam sebulan kepada KPM dan difasilitasi oleh Pendamping Sosial PKH yang sudah mengikuti diklat FDS serta dinyatakan lulus oleh Balai Besar Pendidikan dan Pelatihan Kesejahteraan Sosial (BBPPKS) Kementerian Sosial RI. Kelurahan Pekan Selesai merupakan salah satu Kelurahan di Kecamatan Selesai Kabupaten Langkat memiliki 2 orang pendamping sosial yang bekerja mendampingi pelaksanaan program di lapangan, dengan status sudah mengikuti diklat FDS pada Januari 2018. Kelurahan Pekan Selesai memiliki jumlah 391 KPM yang di bagi dalam kelompok-kelompok FDS. Pembelajaran modul FDS kepada Keluarga Penerima Manfaat PKH di Kelurahan Pekan Selesai sudah di mulai sejak bulan januari 2018.

\section{METODE PENELITIAN}

Penelitian ini menggunakan pendekatan deskriptif kualitatif yaitu menghasilkan data deskriptif berupa kata-kata tertulis atau lisan dari orang-orang dan perilaku yang diamati dari fenomena yang terjadi selama implementasi motode FDS (Family Development Session). Selanjutnya hasil penelitian merupakan deskripsi dari hasilhasil wawancara-wawancara mendalam terhadap subjek penelitian sehingga dapat memberikan gambaran yang jelas mengenai implementasi motode FDS (Family Development Session) Program Keluarga Harapan di Kelurahan Pekan Selesai Kecamatan Selesai Kabupaten Langkat.

Informan penelitian atau seseorang yang memberikan informasi terkait judul penelitian adalah mereka yang terlibat langsung maupun tidak langsung dalam implementasi metode FDS (Family Development Session) Program Keluarga Harapan di Kelurahan Pekan Selesai. Informan adalah orang yang diharapkan dapat memberikan informasi tentang situasi dan kondisi pada latar belakang.

Teknik pengumpulan data merupakan langkah yang paling utama dalam penelitian, karena tujuan utama dari penelitian adalah mendapatkan data. Menurut Bungin (2008) bila dilihat dari segi cara atau teknik pengumpulan data, maka teknik pengumpulan 
data dapat dilakukan dengan observasi, wawancara, angket dan dokumentasi. Dalam penelitian ini teknik pengumpulan data yang dilakukan oleh peneliti dengan tiga metode, yaitu: Observasi bersifat nonpartisipatif, yaitu peneliti tidak terlibat secara langsung dalam kegiatan melainkan mengamati secara independen. Untuk mengetahui dan mengamati kondisi yang sesungguhnya bagaimana implementasi FDS (Family Development Session) baik secara kebijakan di kantor Dinas Sosial Kabupaten Langkat dan juga secara praktik penerapan metode FDS (Family Development Session) di lapangan kepada keluarga penerima manfaat $\mathrm{PKH}$ Kelurahan Pekan Selesai. Melalui teknik observasi ini peneliti mengunjungi kantor Dinas Sosial Kabupaten Langkat, Kantor Kelurahan Pekan Selesai dan selanjutnya mengamati pelaksanaan FDS (Family Development Session) di kelompok penerima manfaat PKH Kelurahan Pekan Selesai.

Dalam melakukan wawancara kepada informan di lapangan, peneliti menyiapkan instrumen penelitian berupa pertanyaanpertanyaan tertulis untuk diajukan, dan mencatat apa yang dikemukakan oleh informan, oleh karena itu wawancara yang digunakan oleh peneliti dilakukan secara mendalam dan terstruktur sehingga dapat dikonstruksikan makna dalam suatu topik tertentu

Pengolahan dan analisis data menggunakan teknik analisis deskriptif kualitatif, yaitu penelitian yang didasarkan data deskriptif dari status, keadaan, sikap, hubungan atau sistem pemikiran suatu masalah yang menjadi objek penelitian. Setelah mendapatkan data-data yang diperoleh dalam penelitian ini, maka langkah selanjutnya adalah mengolah data yang terkumpul dengan menganalisis data, mendeskripsikan data, serta mengambil kesimpulan.

\section{HASIL DAN PEMBAHASAN \\ Implementasi metode FDS (Family Development Session) di Kelurahan Pekan Selesai Kecamatan Selesai Kabupaten Langkat.}

Pelaksanaan FDS merupakan tahapan dalam siklus Program Keluarga Harapan secara besaran. Pelaksanaan FDS di Kelurahan Pekan Selesai sesuai teknis tahapan yang disepakati di tingkat Kabupaten dimulai dengan (1) Tahap sosialisasi dan pembentukan kelompok, (2) Tahap identifikasi masalah, (3) Tahap pembelajaran materi dan (4) Tahap pelaporan. Rangkaian kegiatan $\mathrm{di}$ atas merupakan acuan pendamping sosial di wilayah Kelurahan Pekan Selesai Kecamatan Selesai dalam mengimplementasikan FDS di lapangan.

Tahap sosialisasi merupakan tahap awal dari implementasi metode FDS di lapangan, pada tahapan ini dilaksanakan beberapa kegiatan dalam kurun waktu selama 1 bulan. yang dimulai dengan kegiatan sosialisasi di tingkat Kabupaten yang dilaksanakan oleh Dinas Sosial kepada para pendamping sosial. Hal ini seperti disampaikan oleh Bapak Rusdan Pohan, ST Kepala Bidang Perlindungan Jaminan dan Organisasi Sosial Dinas Sosial Kabupaten Langkat sebagai berikut: Program Keluarga Harapan itu program pusat yang diimplementasikan di daerah Kabupaten, kami selaku pihak Dinas Sosial Kabupaten Langkat tentunya mempunyai tanggungjawab untuk menyampaikan informasi tentang pelaksanaan FDS ini kepada pendamping sosial agar nantinya mereka bisa mulai turun kelapangan untuk mensosialisasikan dan melaksanakannya kepada KPM". Sosialisasi tidak berhenti hanya di tingkat Kabupaten, seperti yang disampaikan oleh Kepala Bidang Perlindungan Jaminan dan Organisasi Sosial sebelumnya bahwa sosialisasi juga berlanjut di tingkat Kecamatan, Kelurahan dan Desa.

Pendapat pendamping sosial ibu Syara Irani terkait kegiatan sosialisasi yang mereka dapatkan dan mereka lakukan, bahwa masih belum ada kegiatan yang menganggendakan khusus sosialisasi materi FDS kepada mereka di tingkat kabupaten, kecamatan atau kelurahan. Selanjutnya pendamping sosial melaksanakan sosialisasi di tingkat kelurahan, namun sedikit yang berbeda dengan cara pendamping dalam melakukan sosialisasi yaitu dengan cara tidak resmi. Pendamping sosial sekedar ngobrol saat bertemu di sela-sela pertemuan rapat koordinasi di Kecamatan dan juga menyampaikannya kembali saat sedang kunjungan ke rumah keluarga penerima manfaat di Kelurahan Pekan Selesai. Walaupun pada saat itu FDS belum diimplementasikan, karena untuk wilayah Langkat sendiri baru dimulai pada tahun 2018 atau sekitar 3 tahun setelah bantuan sosial PKH berjalan. 
Berdasarkan informasi yang peneliti dapatkan, bahwa pemerintah Kelurahan mengetahui adanya pertemuan kelompok bulanan para keluarga penerima manfaat, akan tetapi pemerintah Kelurahan tidak secara jelas mengetahui bahwa kegiatan kelompok tersebut adalah kegiatan belajar FDS yang menggunakan modul-modul pembelajaran. Tahapan akhir sosialisasi kepada keluarga penerima manfaat dilakukan oleh pendamping sosial dengan cara mengumpulkan seluruh warga dampingan. inisitatif untuk membentuk kelompok lebih awal yaitu untuk memudahkan dirinya mengontrol dan menyampaikan informasi kepada warga dampingannya.

Penyampaian informasi kebijakan jika dilakukan sampai di tingkat paling rendah menjadi faktor penentu keberhasilan menjalankan program tersebut. Demikian halnya dengan sosialisasi FDS harus sudah tersampaikan kepada para keluarga penerima manfaat dengan baik, sehingga tidak terjadi pemahaman yang berbeda terkait kebijakan yang diberlakukan.
Tahapan Identifikasi masalah merupakan tahapan yang dilaksanakan oleh pendamping sosial dalam pertemuan kelompok FDS untuk pertama kali. Pada tahapan ini para pendamping sosial melakukan asessment (menggali informasi) kepada masing-masing penerima manfaat. Menggali informasi ini dilakukan dengan teknik MPA (Methodology Participatory Assesment), yaitu sebuah metodologi yang bersifat partisipatif. MPA dikatakan bersifat partisipatif karena para penerima manfaat diminta untuk menyampaikan masalah yang sering mereka temui dan rasakan dalam keluarga mereka. Isu masalah ini merujuk pada lima modul FDS yaitu (1) Pengasuhan anak, (2) perlindungan anak, (3) Ekonomi, (4) Kesehatan dan (5) Kesejahteraan sosial. Jika pendamping sudah mendapatkan isu masalah dari para KPM, maka masalah tersebut diurutkan sesuai jumlah terbanyak masalah yang sama dialami oleh keluarga penerima manfaat dalam kelompok.

Tabel 1. Kelompok FDS Keluarga Penerima Manfaat Program Keluarga Harapan Kelurahan Pekan Selesai

\begin{tabular}{lll}
\hline Nama Kelompok & $\begin{array}{l}\text { Pendamping } \\
\text { Sosial }\end{array}$ & Jumlah Anggota Kelompok \\
\hline I Sei Sekala & Syahra Irani, A.Md & 18 \\
\hline II Ara Tunggal & Syahra Irani, A.Md & 12 \\
\hline III Pekan Selesai & Syahra Irani, A.Md & 27 \\
\hline IV Muka Stasiun & Syahra Irani, A.Md & 24 \\
\hline V Pasar Rodi & Syahra Irani, A.Md & 19 \\
\hline VI Pamah & Syahra Irani, A.Md & 15 \\
\hline VII Ladang Kapas & Syahra Irani, A.Md & 15 \\
\hline VIII Pasar 2 & Syahra Irani, A.Md & 20 \\
\hline IX Pasar 3 & Syahra Irani, A.Md & 16 \\
\hline X Paya Jambu & Syahra Irani, A.Md & 14 \\
\hline Apel & Nina O. Sembiring, S.IP & 18 \\
\hline Cherry & Nina O. Sembiring, S.IP & 29 \\
\hline Naga & Nina O. Sembiring, S.IP & 25 \\
\hline Mangga & Nina O. Sembiring, S.IP & 22 \\
\hline Manggis & Nina O. Sembiring, S.IP & 29 \\
\hline Melon & Nina O. Sembiring, S.IP & 15 \\
\hline Delima & Nina O. Sembiring, S.IP & 38 \\
\hline Lilly & Nina O. Sembiring, S.IP & 35 \\
\hline Total KPM & 391 \\
\hline
\end{tabular}

Sumber : Data FDS E-PKH SDM Kabupaten Langkat Maret 2020 
Berikut ini matriks perbandingan standar pelaksanaan dengan hasil temuan lapangan pada tahapan sosialisasi dan pembentukan kelompok:

Tabel 2. Matriks Pembanding Standar Pelaksanaan dengan Hasil Temuan Lapangan pada tahap Sosialisasi dan Pembentukan Kelompok.

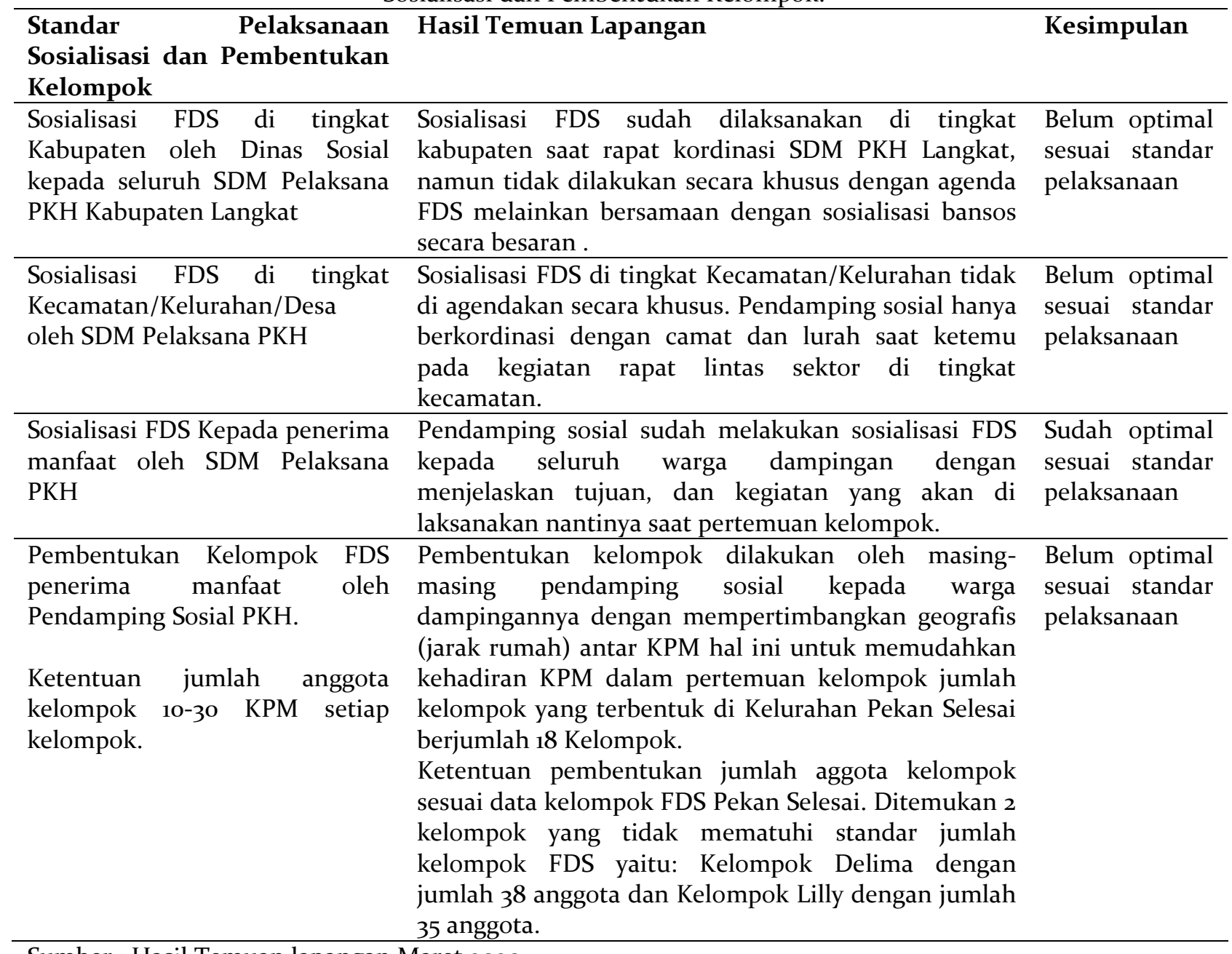

Sumber : Hasil Temuan lapangan Maret 2020

Cara identifikasi masalah yang dilakukan oleh pendamping sosial berbeda-beda, ada yang melakukannya dalam kelompok FDS yang sudah dibagi setelah kegiatan sosialisasi dan ada juga yang melakukannya bersamaan dengan kegiatan sosialisasi awal sesaat sebelum pembagian kelompok. Berikut ini pernyataan Ibu Nurasmi penerima manfaat PKH Kelurahan Pekan Selesai, kami dulu ditanyakan masalah yang sering kami alami dalam keluarga, dan kami disuruh menulisnya di kertas kecil. Banyak dari kami bingung karena tidak terbiasa dengan kegiatan menulis seperti ini. Beberapa dari kami dibantu oleh pendamping untuk menulis. Informasi yang didapatkan peneliti dalam pelaksanaan identifikasi masalah, masih terdapat keluarga penerima manfaat yang belum paham betul tujuan dilakukannya teknik MPA ini.
Berikut tabel jumlah kelompok yang melaksanakan identifikasi masalah dengan MPA (Methodology Participatory Assesment) di Kelurahan Pekan Selesai:

Tabel 3. Kelompok yang melaksanakan Identifikasi dengan teknik MPA

\begin{tabular}{llll}
\hline $\begin{array}{l}\text { Pendamping } \\
\text { Sosial }\end{array}$ & $\begin{array}{l}\text { Kelompok } \\
\text { Dampingan }\end{array}$ & $\begin{array}{l}\text { Sesuai } \\
\text { Tahapan } \\
\text { MPA }\end{array}$ & $\begin{array}{l}\text { Belum } \\
\text { Sesuai } \\
\text { Tahapan } \\
\text { MPA }\end{array}$ \\
\hline Syara Irani & 10 & 7 & 3 \\
\hline $\begin{array}{l}\text { Nina } \\
\text { Oktaviani }\end{array}$ & 8 & 5 & 2 \\
\hline Jumlah & 18 & 12 & 5 \\
\hline
\end{tabular}

Sumber: Hasil wawancara dengan pendamping sosial

Berdasarkan informasi pelaksanaan identifikasi masalah dengan menggunakan 
MPA kepada penerima manfaat di Kelurahan Pekan Selesai, masih belum optimal pelaksanaan. Sebagaimana informasi tabel 3 masih terdapat 5 kelompok dari jumlah total 18 kelompok KPM di Kelurahan Pekan Selesai yang belum bisa melaksanakan MPA sesuai tahapan yang ditentukan, karena kegiatan identifikasi masalah dilakukan pendamping tanpa partisipasi dari penerima manfaat. Hal ini dikarenakan jumlah penerima manfaat juga yang lumayan banyak dan pertimbangan lainnya juga kemampuan pemahaman para keluarga penerima manfaat yang berbedabeda dalam memahami arahan yang diberikan pendamping sosial.

Berikut ini matriks perbandingan standar pelaksanaan dengan hasil temuan lapangan pada tahapan identifikasi masalah:

Tabel 4. Matriks Pembanding Standar Pelaksanaan dengan Hasil Temuan Lapangan pada tahap Identifikasi Masalah

\begin{tabular}{|c|c|c|}
\hline SOP Tahap Identifikasi Masalah & Hasil Temuan Lapangan & $\begin{array}{l}\text { Kesimpulan } \\
\text { Pelaksanaan }\end{array}$ \\
\hline $\begin{array}{l}\text { Pendamping sosial menggali masalah yang } \\
\text { sering di temukan oleh KPM di lingkungan } \\
\text { keluarga mereka dengan menggunakan teknik } \\
\text { MPA (Methode partisipatory Assesment). } \\
\text { Partisipasi KPM dibutuhkan untuk } \\
\text { mengungkapkan masalah. }\end{array}$ & $\begin{array}{l}\text { Dari } 18 \text { total kelompok di } \\
\text { Kelurahan Pekan Selesai di peroleh } \\
\text { informasi } 5 \text { kelompok yang tidak } \\
\text { melaksanakan identifikasi masalah } \\
\text { sesuai standar pelaksanaan. }\end{array}$ & $\begin{array}{l}\text { Belum optimal } \\
\text { sesuai standar } \\
\text { pelaksanaan }\end{array}$ \\
\hline $\begin{array}{l}\text { Pendamping sosial berperan memfasilitasi para } \\
\text { penerima manfaat untuk mengungkap masalah } \\
\text { mereka dengan mengacu pada isu } \\
\text { pembelajaran modul FDS: Perlindungan anak, } \\
\text { Pengasuhan anak anak, Kesehatan Gizi, } \\
\text { Ekonomi dan usaha, serta Kesejahteraan sosial } \\
\text { disabilitas dan lanjut usia. }\end{array}$ & $\begin{array}{l}\text { Terdapat } 5 \quad \text { kelompok yang } \\
\text { identifikasi } \\
\text { penentuan modul pembelajaran } \\
\text { dalam kelompok di lakukan di } \\
\text { bersamaan saat pertemuan } \\
\text { sosialisasi, }\end{array}$ & $\begin{array}{l}\text { Belum optimal } \\
\text { sesuai standar } \\
\text { pelaksanaan }\end{array}$ \\
\hline
\end{tabular}

Sumber: Hasil Temuan lapangan Maret 2020

Tahapan pembelajaran materi dalam FDS merupakan kegiatan inti dari metode ini, pendamping sosial menjalankan fungsi fasilitator untuk menyampaikan materi dari modul yang ada. Seperti dijelaskan sebelumnya bahwa penentuan pemilihan modul pembelajaran sudah dilakukan di tahap identifikasi masalah. Dalam pembelajaran pendamping sosial menyampaikan materi dalam satu kali pertemuan dengan durasi waktu maksimal 120 menit. Adapun modul pembelajaran yang disampaikan pendamping sosial dalam metode FDS antara lain Pengasuhan anak, perlindungan anak, Ekonomi, Kesehatan dan Kesejahteraan sosial.

Dalam memfasilitasi pembelajaran materi FDS, pendamping sosial yang menjalankan peran sebagai fasilatator harus melaksanakan langkah-langkah sebagai berikut: Penyampaian Judul Modul Besar; Penyampaian Judul Sesi; Penyampaian Tujuan Pembelajaran; Penyampaian Inti Pembelajaran; Penutup.

Pelaksananaan pembelajaran materi FDS kepada penerima manfaat di Kelurahan Pekan Selesai yang difasilitasi langsung pendamping sosial, seperti yang disampaikan oleh Ibu Nina Oktapiani Sembiring dan Ibu Syara Irani Pendamping Sosial Kelurahan Pekan Selesai :Di tahun 2018 saya memfasiliatsi FDS petama kali menyampaikan materi Pengasuhan Anak kepada keluarga penerima manfaat di kelompok Melon. waktu pertama kali pelaksanaan para peserta itu masih canggung-canggung karena belum terbiasa. Saya melakukan ice breaking kepada mereka untuk membantu mencairkan suasana seperti tepuk P2K2 dan tepuk semangat. Setelah suasana mencair baru dilanjutkan dengan inti pembelajaran tentang pengasuhan anak.

Pelaksanaan pembelajaran materi FDS tidak terlepas juga dengan keikutsertaan para penerima manfaat dalam kelompok, seperti yang disampaikan oleh Ibu Nurasmi dan Ibu Musriatik penerima manfaat PKH Kelurahan Pekan Selesai sebagai berikut: waktu belajar tentang Kesehatan kami diberitahu tentang tujuan pembelajaran, kemarin itu membahas pentingnya kesehatan bagi ibu hamil. Pendamping waktu itu juga mewajibkan anggota kelompok kami yang sedang 
mengandung untuk melakukan pemeriksaan kesehatan itu harus di Bidan dan jangan ke dukun beranak yang ada di kampung. Implementasi pembelajaran materi FDS yang sudah di mulai pendamping sosial sejak februari 2018 di kelompok masing-masing wajib melaporkan modul pembelajaran yang sudah mereka fasilitasi di dalam kelompok dibulan berkenan.

Selanjutnya observasi yang dilakukan peneliti saat kegiatan pembelajaran materi FDS di kelompok "Sembilan IX Pasar 3" dampingan Ibu Syara Irani, peneliti mencatat hasil observasi sebagai berikut: memfasilitasi pembelajaran modul Pengasuhan dan Perlindungan anak Sesi 3 yaitu Memahami Cara anak usia Dini Belajar. Ibu syara Irani melakukan Langkah (1) yaitu membuka pertemuan kelompok dengan mereview hasil pertemuan bulan sebelumnya. Selanjutnya menyampaikan langkah-langkah berikutnya sesuai modul antara lain: Langkah (2) memuji Anak, Langkah (3) Memberikan penghargaan saat anak melakukan hal baik, Langkah (4) Dampak negatif kekerasan fisik dan non fisik pada anak, Langkah (5) Berbagai cara memngurangi perilaku buruk anak, Langkah (6) penutup. Temuan peneliti dari observasi terdapat 2 orang penerima manfaat yang memiliki keterbatasan kemampuan membaca dan menuli, sehingga tidak bisa menggunakan bahan bacaan berupa buku pintar dan poster selama pembelajaran.

Pembelajaran materi FDS di wilayah dampingan Kelurahan Pekan Selesai dapat kita lihat melalui tabel realisasi pembelajaran materi FDS sebagai berikut:

Tabel 5. Realisasi Pembelajaran Materi FDS kepada KPM

\begin{tabular}{|c|c|c|c|c|c|}
\hline Nama kelompok & Modul PKPU & Modul LKG & Modul PPA & Modul PA & Modul KESSOS \\
\hline I sei sekala & $\sqrt{ }$ & $\sqrt{ }$ & $\sqrt{ }$ & $\sqrt{ }$ & - \\
\hline II Ara Tunggal & $\sqrt{ }$ & $\sqrt{ }$ & $\sqrt{ }$ & $\sqrt{ }$ & - \\
\hline III Pekan Selesai & $\sqrt{ }$ & $\sqrt{ }$ & $\sqrt{ }$ & $\sqrt{ }$ & $\sqrt{ }$ \\
\hline IV Muka Stasiun & $\sqrt{ }$ & $\sqrt{ }$ & $\sqrt{ }$ & $\sqrt{ }$ & $\sqrt{ }$ \\
\hline V Pasar Rodi & $\sqrt{ }$ & $\sqrt{ }$ & $\sqrt{ }$ & $\sqrt{ }$ & $\sqrt{ }$ \\
\hline VI Pamah & $\sqrt{ }$ & $\sqrt{ }$ & $\sqrt{ }$ & $\sqrt{ }$ & - \\
\hline VII Ladang Kapas & $\sqrt{ }$ & $\sqrt{ }$ & $\sqrt{ }$ & $\sqrt{ }$ & - \\
\hline VIII Pasar 2 & $\sqrt{ }$ & $\sqrt{ }$ & $\sqrt{ }$ & $\sqrt{ }$ & $\sqrt{ }$ \\
\hline IX Pasar 3 & $\sqrt{ }$ & $\sqrt{ }$ & $\sqrt{ }$ & $\sqrt{ }$ & $\sqrt{ }$ \\
\hline X Paya Jambu & $\sqrt{ }$ & $\sqrt{ }$ & $\sqrt{ }$ & $\sqrt{ }$ & - \\
\hline Apel & $\sqrt{ }$ & $\sqrt{ }$ & $\sqrt{ }$ & $\sqrt{ }$ & - \\
\hline Cherry & $\sqrt{ }$ & $\sqrt{ }$ & $\sqrt{ }$ & $\sqrt{ }$ & $\sqrt{ }$ \\
\hline Naga & $\sqrt{ }$ & $\sqrt{ }$ & $\sqrt{ }$ & $\sqrt{ }$ & - \\
\hline Mangga & $\sqrt{ }$ & $\sqrt{ }$ & $\sqrt{ }$ & $\sqrt{ }$ & - \\
\hline Manggis & $\sqrt{ }$ & $\sqrt{ }$ & $\sqrt{ }$ & $\sqrt{ }$ & $\sqrt{ }$ \\
\hline Melon & $\sqrt{ }$ & $\sqrt{ }$ & $\sqrt{ }$ & $\sqrt{ }$ & - \\
\hline Delima & $\sqrt{ }$ & $\sqrt{ }$ & $\sqrt{ }$ & $\sqrt{ }$ & $\sqrt{ }$ \\
\hline Lilly & $\sqrt{ }$ & $\sqrt{ }$ & $\sqrt{ }$ & $\sqrt{ }$ & $\sqrt{ }$ \\
\hline JUMLAH & 18 & 18 & 18 & 18 & 9 \\
\hline
\end{tabular}

Sumber : Data FDS E-PKH SDM Kabupaten Langkat Maret 2020

Berdasarkan informasi tabel 5 menyatakan bahwa kelompok KPM di Kelurahan Pekan Selesai berjumlah 18 kelompok. Sesuai data yang ada terkonfirmasi terdapat 9 kelompok penerima manfaat yang masih belum mempelajari modul Kesejahateraan Sosial.
Berikut ini matriks perbandingan standar pelaksanaan dengan hasil temuan lapangan pada tahapan pembelajaran materi: Tabel 6. Matriks Pembanding Standar Pelaksanaan dengan Hasil Temuan Lapangan pada tahap Pembelajaran Materi 


\begin{tabular}{|c|c|c|}
\hline $\begin{array}{l}\text { SOP Tahap Pembelajaran } \\
\text { Materi }\end{array}$ & Hasil Temuan Lapangan & Kesimpulan Pelaksanaan \\
\hline $\begin{array}{l}\text { Penyampaian judul modul, } \\
\text { sesi pembelajaran, tujuan } \\
\text { pembelajaran, penyampaian } \\
\text { inti pembelajaran dan } \\
\text { penutup. }\end{array}$ & $\begin{array}{l}\text { Pendamping Sosial sudah melaksanakan } \\
\text { dan memfasilitasi langkah-langkah } \\
\text { pembelajaran materi sesuai dengan yang } \\
\text { tertera dalam modul fasilitator }\end{array}$ & $\begin{array}{l}\text { Sudah optimal sesuai } \\
\text { standar pelaksanaan }\end{array}$ \\
\hline $\begin{array}{l}\text { Penggunaan Toolkit/alat } \\
\text { peraga pembelajaran: Modul, } \\
\text { Flipchart, buku pintar, poster } \\
\text { dan brosur. }\end{array}$ & $\begin{array}{l}\text { Terdapat beberapa toolkit/alat peraga yang } \\
\text { masuk dalam kategori komponen bahan } \\
\text { ajar tidak bisa di pergunakan oleh KPM } \\
\text { diantaranya: penggunaan buku pintar, } \\
\text { poster, dan brosur pembelajran. } \\
\text { Penggunaan bahan ajar tersebut } \\
\text { dikarenakan keterbatasan penerima } \\
\text { manfaat dalam membaca dan menulis. }\end{array}$ & $\begin{array}{l}\text { Belum optimal sesuai } \\
\text { standar pelaksanaan }\end{array}$ \\
\hline $\begin{array}{l}\text { Waktu pembelajaran yaitu } \\
\text { maksimal } 120 \text { menit }\end{array}$ & $\begin{array}{l}\text { Pertemuan FDS sesuai dengan hasil } \\
\text { wawancara dengan informan dan observasi } \\
\text { juga yang di lakukan peneliti saat kegiatan } \\
\text { pertemuan menunjukkan bahwa } \\
\text { pelaksanaan pembelajran tidak lebih dari } \\
120 \text { menit. Adanya agenda/pembahasan } \\
\text { lain setelah pembelajaran materi membuat } \\
\text { pendamping harus menyesuaikan waktu } \\
\text { dalam memfasilitasi pertemuan. }\end{array}$ & $\begin{array}{l}\text { Sudah optimal sesuai } \\
\text { standar pelaksanaan }\end{array}$ \\
\hline
\end{tabular}

Sumber : Hasil Temuan lapangan Maret 2020

Tahapan pelaporan merupakan bagian akhir dari tahapan pelaksanaan FDS, pendamping membuat laporan sebagai bentuk kewajiban dari pekerjaan yang sudah mereka laksanakan di lapangan. Masing-masing pendamping sosial mempunyai kewajiban yang sama yaitu membuat laporan pelaksanaan FDS sesuai dengan jumlah pertemuan yang sudah mereka laksanakan setiap bulannya dan dilaporkan setiap akhir bulan berkenaan. Laporan FDS sejak bulan Februari 2018 sampai dengan bulan Agustus 2019, PKH masih menerapkan pelaporan berjenjang melalui pengiriman file dengan cara manual melalui bagian administrasi pangkalan data PKH Dinas Sosial Kabupaten, selanjutnya diteruskan pengiriman ke administrasi pangkalan data PKH Dinas Sosial Provinsi dan terkahir secara kolektif di kirim ke Bagian data Direktorat Jaminan Sosial Keluarga Kementerian Sosial RI.

Berikut Pernyataan Kordinator Kabupaten PKH Langkat Bapak Zaki Amani, SH dan pendamping sosial Ibu Syara Irani Pendamping Sosial PKH Kelurahan Pekan Selesai: tahun 2018 sampai Agustus 2019
Pelaporan FDS dikirim bersamaan dengan laporan bulanan pelaksanan PKH secara keseluruhan dalam bentuk file excel dan word, itu biasanya tiap akhir bulan tanggal 28-29 pengumpulan laporan. Kalau pendamping sudah menyerahkan semua maka laporan pendamping kita rekap di Kabupaten untuk kita teruskan ke Provinsi

Seiring berkembangnya teknologi ke arah digitalisasi Kementerian Sosial RI mengembangkan sebuah aplikasi berbasis IT yaitu E-PKH (Elektronik Program Keluarga Harapan) yang mengubah semua sistem pelaporan berbasis elektronik dengan cara pengimputan data melalui aplikasi E-PKH tersebut. Berikut Alur Pelaporan FDS melalui E-PKH: Perubahan pelaporan dengan sistem upload dan input data melalui aplikasi E-PKH menjadi kemudahan bagi para pendamping sosial dalam melaporkan kegiatan FDS yang sudah mereka laksanakan.

Berikut ini matriks perbandingan standar pelaksanaan dengan hasil temuan lapangan pada tahapan pelaporan: 
Tabel 7. Matriks Pembanding Standar Pelaksanaan dengan Hasil Temuan Lapangan pada tahap Pelaporan

\begin{tabular}{|c|c|c|}
\hline $\begin{array}{ll}\text { SOP } & \text { Tahap } \\
\text { Pelaporan } & \end{array}$ & Hasil Temuan Lapangan & $\begin{array}{l}\text { Kesimpulan } \\
\text { Pelaksanaan }\end{array}$ \\
\hline 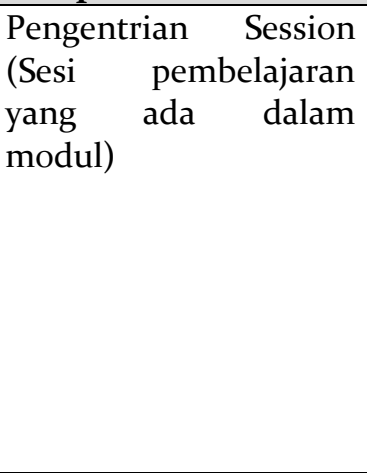 & $\begin{array}{l}\text { Pendamping sosial Kelurahan Pekan Selesai } \\
\text { tahun 2018-2019 melakukan pelaporan } \\
\text { berjenjang manual melalui Administrasi } \\
\text { Pangkalan Data di Kabupaten. } \\
\text { Tahun } 2019 \text { Pendamping sosial Kelurahan } \\
\text { Pekan Selesai mulai melakukan pelaporan } \\
\text { menggunakan akun masing-masing } \\
\text { pendamping melalui aplikasi E-PKH. } \\
\text { Pendamping Sosial mengentri daftar kelompok } \\
\text { dan anggota dalam aplikasi sesuai data } \\
\text { kelompok warga dampingan di lapangan. }\end{array}$ & $\begin{array}{l}\text { Sudah optimal sesuai } \\
\text { standar pelaksanaan }\end{array}$ \\
\hline $\begin{array}{l}\text { Peng-inputan } \\
\text { materi/Sesi } \quad \text { Modul } \\
\text { yang sudah difasilitasi } \\
\text { kepada } \quad \text { penerima } \\
\text { manfaat. }\end{array}$ & $\begin{array}{l}\text { Pendamping Sosial Kelurahan Pekan Selesai } \\
\text { setiap bulannya meng-input Sesi pembelajaran } \\
\text { Modul sesuai pelaksanaan FDS dibulan } \\
\text { berkenan. }\end{array}$ & $\begin{array}{l}\text { Sudah optimal sesuai } \\
\text { standar pelaksanaan }\end{array}$ \\
\hline $\begin{array}{l}\text { Upload absensi/daftar } \\
\text { hadir, notula } \\
\text { pembelajaran materi } \\
\text { dan foto kegiatan } \\
\text { pembelajaran materi }\end{array}$ & $\begin{array}{l}\text { Pendamping Sosial Kelurahan Pekan Selesai } \\
\text { melampirkan bukti pelaksanaan FDS dibulan } \\
\text { berkenan dengan mengimput daftar hadir KPM, } \\
\text { Notula hasil pembelajaran FDS dan foto } \\
\text { kegiatan FDS. }\end{array}$ & $\begin{array}{l}\text { Sudah optimal sesuai } \\
\text { standar pelaksanaan }\end{array}$ \\
\hline $\begin{array}{l}\text { Persetujuan } \\
\text { (approval)oleh } \\
\text { Kordinator } \\
\text { Kabupaten }\end{array}$ & $\begin{array}{l}\text { Kordinator PKH Kabupaten Langkat } \\
\text { memferifikasi laporan pendamping dan } \\
\text { memberi approval melalui akun E-PKH untuk } \\
\text { menyetujui pelaporan yang akan diteruskan di } \\
\text { JSK Pusat Kemensos RI }\end{array}$ & $\begin{array}{l}\text { Sudah optimal sesuai } \\
\text { standar pelaksanaan }\end{array}$ \\
\hline
\end{tabular}

Sumber : Hasil Temuan lapangan dan dokumentasi E-PKH Kab Langkat, Maret 2020

\section{SIMPULAN}

Implemetasi FDS (Family Development Session) di wilayah Kelurahan Pekan Selesai pada masing-masing tahapan diperoleh informasi yaitu: Tahapan sosialisasi dan pembentukan kelompok sudah dilaksanakan secara berjenjang dari tingkat kabupaten, kecamatan, diteruskan di tingkat kelurahan dan terakhir kepada penerima manfaat. Untuk pembentukan kelompok, pertimbangan geografis dan lokasi rumah penerima manfaat menjadi pertimbangan utama pendamping dalam membentuk kelompok FDS penerima manfaat. Tahapan identifikasi masalah, pendamping sosial sudah melaksanakan identifikasi masalah walaupun belum optimal untuk semua kelompok, karena masih ditemukan pelaksanaan identifikasi masalah yang dilaksanakan bersamaan saat sosialisasi dan pembentukan kelompok, padahal tahapan ini sebaiknya dilaksanakan setelah tahapan sosialisasi. Pertimbangan kemampuan penerima manfaat dalam mengikuti instruksi yang disampaikan oleh pendamping sosial belum bisa dilakukan dengan baik. Sehingga dalam tahapan ini secara teknis keputusan lebih didominasi oleh pendamping sosial. Tahapan pembelajaran materi, pendamping sosial sudah melaksanakan penyampaian judul modul besar, penyampaian judul sesi, penyampaian tujuan pembelajaran dan inti pembelajaran kepada penerima manfaat dalam kelompok. Yang menjadi informasi dalam tahapan ini yaitu belum optimalnya penggunaan bahan ajar saat penyampaian materi seperti Flipchart, buku pintar, poster, brosur. Keterbatasan kemampuan penerima manfaat seperti belum bisa baca dan tulis menjadi hambatan dalam penggunaan bahan ajar di tahapan ini. Tahap Pelaporan, pendamping sosial kelurahan Pekan Selesai sudah optimal melaksanakan kewajibannya untuk melakukan laporan pelaksanaan FDS setiap bulannya, sebuah kemudahan dalam pelaporan karena sudah berbasis aplikasi (E$\mathrm{PKH})$, hal ini memudahkan pendamping sosial. 
Terkait implemetasi FDS di Kelurahan Pekan Selesai, semua pihak antara lain: Dinas Sosial, Kordinator Kabupaten PKH, Kordinator Kecamatan Selesai dan Pendamping sosial Kelurahan Pekan Selesai sudah menjalankan tugas tahapan implementasi FDS. Akan tetapi pada pelaksanaan setiap tahapan masih mengalami beberapa hambatan, hal ini yang menjadi pelaksanaan setiap tahapan belum bisa berjalan secara optimal sesuai dengan aturan pelaksanaan yang ada

\section{DAFTAR PUSTAKA}

Ahmad, T., Erowati, D., Dan Wijayanto. (2005). Upaya Penanggulangan Kemiskinan Berbasis Pemberdayaan Masyarakat Lokal. Jurnal Masyarakat Kebudayaan Dan Politik. 5(4): 20-25.

Annur Reza Attabiurrobbi. (2013). Faktor-faktor yang mempengaruhi kemiskinan di Kecamatan Jekulo dan Mejobo Kabupaten Kudus. Economics Development Analysis Journal. 2(4): 413.

Anwar, S. (2015). Karakteristik Keluarga Menurut Peringkat Kemiskinan: Studi pendahuluan untuk perumusan kriteria fakir miskin. Informasi. 17(1):50-53

Bagong, S. (2001). Kemiskinan dan pemberdayaan Masyarakat Miskin. Jurnal Masyarakat Kebudayaan dan Politik. 5(4): 25-42.

Bungin, B. (2008). Analisis Data Penelitian Kualitatif. Jakarta: Raja Grafindo Persada.

Direktorat Jaminan Sosial Keluarga. (2018). Petunjuk Teknis Penyaluran Bantuan Sosial Non Tunai Program Keluarga Harapan. Jakarta: Kementerian Sosial RI.

Elly, K. (2018). Pengaruh Pemberdayaan Keluarga Penerima Manfaat Program Keluarga Harapan melalui Family Development Session. Jurnal PKS. 17(2): 92.

Erna, S. (2015). Upaya Program terpadu penanggulangan kemiskinan di Kota Surabaya. Jurnal Ilmu Sosial dan Ilmu Politik. 5(4): 24-48.

Farida, U., \& Sutjiatmi, S.. (2018). Efektivitas Program keluarga Harapan (PK) dalam meningkatkan Kesejahteraan Masyarkat di Desa Kupu Kecamatan Dukuhturi Kabupaten Tegal. Pancasakti Government Juornal.
Jadmika, S., Noor, I., dan Suryadi. (2015). Implementasi Program Pemberdayaan Rumah Tangga Sangat Miskin. Jurnal Reformasi Administrasi Publik Universitas Brawijaya. 5(1): 2-6.

Joko, S. (2018). Pemberdayaan Masyarakat: Perspektif komunikasi, organisasi, budaya dan politik. Jurnal Fisip Universitas Sudirman dan Yayasan Litearsi Bangsa.

Mardikanto, T., dan Subianto, P. (2017). Pemberdayaan Masyarakat dalam Perspektif Kebijakan Publik. Bandung: Alfabeta.

Nano, P. (2009). Memahami kemiskinan dan strategi penanggulangannya. Jurnal Ekonomi dan Studi pembangunan. 9(1): 56-68.

Nasdian, F.T. (2015). Pengembangan Masyarakat. Departemen Sains dan pengembangan Masyarakat Fakultas Ekologi Manusia IPB dan Yayasan Pustaka Obor Indonesia. Jakarta

Petunjuk umum pelaksanaan teknis Program Keluarga Harapan 2020

Sabarguna, B. (2008). Analisis Data pada Penelitian Kualitatif. Jakarta: UI-Press.

Setyawan, D. (2017). Pengantar Kebijakan Publik. Malang: Inteligensia.

Soetomo. (2010). Strategi-Strategi Pembangunan Masyarakat. Yogyakarta: Pustaka Pelajar

Suharto, E. (2005). Membangun Masyarakat Memberdayakan Rakyat. Bandung: PT Refika Aditama.

Suharto, E. (2015). Analisis Kebijakan Publik. Panduan Praktis Mengkaji Masalah dan Kebijakan Sosial. Bandung: Alfabeta.

Sulaeman, E.S. (2016). Pemberdayaan Masyarakat di Bidang Kesehatan. Yogyakarta: Gadjah Mada University Press.

Suprayogi, S.Y. (2016). Program penanggulangan kemiskinan pekotaan. Jurnal Analisis Dan Pelayanan Publik. 5(1): 113-119.

Tangkilisan, H.N.S, (2003). Implementasi Kebijakan Publik. Jakarta: Lukman Offset.

Tirani, O. (2017). Implementasi Program Keluarga Harapan di Dinas Sosial Kabupaten Poso. Jurnal Katalogis. 5(6).1-9.

Wahab, S.A. (2016). Analisis Kebijakan.Model-model implementasi kebijakan publik. Jakarta: PT Bumi Aksara.

Yusuf, M. (2014). Metode Penelitian.Kuantitatif. Kualitatif dan Penelitian gabungan. Jakarta: Pramedia Group. 